\title{
Estrogen Receptors in the Medial Amygdala Inhibit the Expression of Male Prosocial Behavior
}

\author{
Bruce S. Cushing, ${ }^{1,2,3}$ Adam Perry, ${ }^{3}$ Sergei Musatov, ${ }^{4,5}$ Sonoko Ogawa, ${ }^{6}$ and Eros Papademetriou ${ }^{3}$ \\ ${ }^{1}$ Department of Biology and ${ }^{2}$ Integrated Bioscience Program, The University of Akron, Akron, Ohio 44325-3908, ${ }^{3}$ The Brain-Body Center, Department of \\ Psychiatry, University of Illinois at Chicago, Chicago, Illinois 60612, ${ }^{4}$ Neurologix, Fort Lee, New Jersey $07024,{ }^{5}$ Laboratory of Neurobiology and Behavior, \\ The Rockefeller University, New York, New York 10021, and ${ }^{6}$ Kansei Behavioral and Brain Sciences Graduate School of Comprehensive Human Sciences, \\ University of Tsukuba, Tsukuba, Ibaraki 305-8577, Japan
}

Studies using estrogen receptor $\alpha(\mathrm{ER} \alpha)$ knock-out mice indicate that $\mathrm{ER} \alpha$ masculinizes male behavior. Recent studies of ER $\alpha$ and male prosocial behavior have shown an inverse relationship between ER $\alpha$ expression in regions of the brain that regulate social behavior, including the medial amygdala (MeA), and the expression of male prosocial behavior. These studies have lead to the hypothesis that low levels of $\mathrm{ER} \alpha$ are necessary to "permit" the expression of high levels of male prosocial behavior. To test this, viral vectors were used to enhance ER $\alpha$ in male prairie voles (Microtus ochrogaster), which display high levels of prosocial behavior and low levels of MeA ER $\alpha$. Adult male prairie voles were transfected with $\mathrm{ER} \alpha$ in the $\mathrm{MeA}(\mathrm{MeA}-\mathrm{ER} \alpha)$ or the caudate-putamen (ER $\alpha$ control) or luciferase (MeAsite-specific control), and 3 weeks later tested for spontaneous alloparental behavior and partner preference. Enhancing ER $\alpha$ in the MeA altered/reduced male prosocial behavior. Only one-third of MeA-ER $\alpha$ males, compared with all control males, were alloparental. MeA$\mathrm{ER} \alpha$ males also displayed a significant preference for a novel female. This is a critical finding because the manipulations of neuropeptides, oxytocin and vasopressin, can inhibit the formation of a partner preference, but do not lead to the formation of a preference for a novel female. The results support the hypothesis that low levels of $\mathrm{ER} \alpha$ are necessary for high levels of male prosocial behavior, and provide the first direct evidence that site-specific $\mathrm{ER} \alpha$ expression plays a critical role in the expression of male prosocial behavior.

Key words: estrogen receptor $\alpha$; Microtus ochrogaster; transfection; viral vector; aggression; amygdala

\section{Introduction}

Estrogen plays a critical role in the expression of male social behavior. Studies using estrogen receptor (ER) knock-out mice indicate that $\operatorname{ER} \alpha$ and $\operatorname{ER} \beta$ regulate different aspects of male behavior. $\mathrm{ER} \beta$ is involved in defeminization (Kudwa et al., 2005), anxiety, and cognition (Krezel et al., 2001), whereas ER $\alpha$ masculinizes behavior (Ogawa et al., 1998; Wersinger et al., 1997). Although some males display high levels of prosocial behavior and positive affiliative behavior, masculine behavior is typically associated with low levels of prosocial behavior and high levels of aggression. The expression of high levels of prosocial behavior requires a reduction of "typical" masculine behavior. It has been hypothesized that decreasing ER $\alpha$ within the social neural circuit is "necessary" for the expression of high levels of prosocial behavior (Cushing et al., 2004; Cushing and Wynne-Edwards, 2006).

Comparative studies support this hypothesis. Illinois prairie voles (Microtus ochrogaster) are highly social, forming pair bonds and providing biparental care. However, Kansas males are signif-

\footnotetext{
Received May 2, 2008; revised Aug. 24, 2008; accepted Aug. 24, 2008.

This work was supported by National Institute of Mental Health Grants MH068278 and MH001992 (B.S.C.). We thank K. Kramer and N. Cushing for their comments and suggestions on this manuscript and K. Sharer for stereotaxic advice.

Correspondence should be addressed to Bruce S. Cushing, Department of Biology and Integrated Bioscience Program, The University of Akron, Akron, OH 44325-3908. E-mail: cbruce@uakron.edu. DOI:10.1523/JNEUROSCI.1928-08.2008

Copyright $\odot 2008$ Society for Neuroscience $\quad$ 0270-6474/08/2810399-05\$15.00/0
}

icantly less social (Cushing and Kramer, 2005a) and express significantly higher levels of ER $\alpha$ in the medial amygdala (MeA) and bed nucleus of the stria terminals (BST) than Illinois males (Cushing et al., 2004). Socially monogamous pine voles (M. pinetorum) express lower levels of $\mathrm{ER} \alpha$ than the polygynous meadow (M. pennsylvanicus) and montane voles (M. montanus) (Cushing and Wynne-Edwards, 2006). Finally, male ER $\alpha$ in species of two dwarf hamsters (Phodopus sp.) that differ in social behavior mirrored $\mathrm{ER} \alpha$ expression within prairie vole populations (Cushing and Wynne-Edwards, 2006).

Changes in ER $\alpha$ expression are correlated with prosocial behavior. In male prairie voles, neonatal castration eliminated alloparental behavior (Lonstein et al., 2002) and the ability of neuropeptides to stimulate pair bond formation (Cushing et al., 2003), whereas significantly increasing $\operatorname{ER} \alpha$ in specific brain regions, including the MeA (Cushing and Kramer, 2005b). Longday male Siberian hamsters (Phodopus sungorus) are nonaggressive, although aggression increases under short days, which is associated with increased ER $\alpha$ (Kramer et al., 2008). Finally, in mice male aggression has been associated with individual variation in $\operatorname{ER} \alpha$ (Trainor et al., 2006). These findings are significant, but correlative. Therefore our goal was to increase $\operatorname{ER} \alpha$ in the MeA of male prairie voles and test the prediction that this would disrupt prosocial behavior.

This study focused on the MeA. MeA ER $\alpha$ is inversely correlated with male prosocial behavior (Hnatczuk et al., 1994; Cush- 
ing et al., 2004; Cushing and Wynne-Edwards, 2006). Conspecific odors activate the vomeronasal organ, triggering the MeA and BST, leading to stimulation of the rest of the social neural circuit (Newman, 1999). Additionally, the MeA innervates the "reward" system via the ventral pallidum, and the reward system is critical for long-term social bond formation (Young et al., 2005). Finally, the MeA regulates social recognition/memory (Ferguson et al., 2001), which is a necessary for long-term social bond formation. We are not suggesting that the MeA is the primarily responsible for regulating specific social behaviors, but that it is critical for the initiation of social responses and therefore changes in MeA can and will impact many aspects of the social response.

\section{Materials and Methods}

\section{Animal husbandry}

Animals used in this study were laboratory-reared prairie voles that originated from wild stock trapped near Urbana, IL. Animals were housed under a $14 \mathrm{~h} / 10 \mathrm{~h}$ light/dark cycle and provided high fiber rabbit chow and water ad libitum. Animals were housed in accordance with the United States Department of Agriculture and National Institutes of Health guidelines and all procedures were approved by the University of Illinois at Chicago Animal Care and Use Committee before undertaking any experimental manipulation.

\section{Viral vector transfection}

To achieve site-specific overexpression of ER $\alpha$ in the MeA, adult males (60-70 d of age) were stereotactically injected, bilaterally, with adenoassociated viral (AAV) vectors encoding human ER $\alpha$. The site of the MeA was determined to be $-1.25 \mathrm{~mm}$ anteroposterior, $\pm 1.65 \mathrm{~mm}$ mediolateral, and $-5.8 \mathrm{~mm}$ dorsal from bregma. Two controls were established. Site-specific controls were generated by transfecting the MeA of males with a similar vector encoding firefly luciferase cDNA, and ER $\alpha$ controls were generated by transfecting the caudate-putamen with ER $\alpha$. Caudate neurons do not express $\mathrm{ER} \alpha$. The AAV vectors used in this study have been described previously in detail (Musatov et al., 2006). Briefly, the vectors express short hairpin RNA containing ER $\alpha$ (GGCATGGAGCATCTCTACA) or luciferase (CCGCTGGAGAGCAACTGCAT) target sequences under the control of the human $\mathrm{H} 1$ promoter. In addition, both vectors were designed to express enhanced green fluorescent protein (GFP) as a reporter to visualize transfection neurons and placed under a control of a hybrid cytomegalovirus/chicken- $\beta$-actin promoter to ensure stable long-term expression. Vector stocks were generated using a helper-free AAV-2 plasmid transfection system, purified by heparin affinity chromatography and dialyzed against PBS as described previously (Clark et al., 1999). AAV genomic titers were determined by quantitative PCR and adjusted to 109 particles per microliter. Three weeks after transfection males began behavioral testing. After completion of behavioral testing, males were killed to analyze the efficiency of gene transfer, and behavioral data were only analyzed in males in which transfection was verified.

Verification of transfection. After completion of the social preference test, brains from experimental animals were fixed using transcardial perfusion, sectioned at $30 \mu \mathrm{m}$ on a freezing sliding microtome, and then the free-floating sections were stained for $\mathrm{ER} \alpha$ using standard $\mathrm{AB}$ immunocytochemistry (for complete details, see Cushing et al., 2004). The human-specific primary antibody RM9101-s (Neomarkers; 1:1000 dilution) was used to label transfected $\mathrm{ER} \alpha$ and then visualized using DAB. RM9101-s does not label prairie vole $\mathrm{ER} \alpha$. Therefore, all ER $\alpha$ observed with this antibody were the product of transfection. Successful transfection was determined qualitatively by visually examining ER $\alpha$ expression using a Nikon E-800 microscope. It should be noted that there were no animals that display only a few transfected $\mathrm{ER} \alpha$-immunoreactive cells, and transfected males either displayed no or a significant amount of transfected $\operatorname{ER} \alpha$. Figure $1 a$ shows a typical level of transfected $\operatorname{ER} \alpha$ expression, which is compared with nontransfected ER $\alpha$ expression seen in Figure $1 b$. Only animals that showed at least unilateral $\mathrm{ER} \alpha$ expression resulting from transfection in the $\mathrm{MeA}$, were used in subsequent analysis of behavior data. Luciferase expression was determined by examining tissue for GFP expression (see Fig. 1c).

\section{Behavior}

Alloparental test. Males participated in a standard alloparental test (Cushing and Kramer, 2005a; Trainor et al., 2006; Young et al., 2005). Males were placed in an alloparental test arena consisting of two cages $(12 \times 18 \times 28 \mathrm{~cm})$ connected by a plastic tunnel. Males were allowed 30 min to adapt to the arena before a 1- to 3 -d-old pup was placed in one of the two cages. The behavior of the male was videotaped and analyzed for $10 \mathrm{~min}$ after entrance into the pup's cage, or for $30 \mathrm{~min}$ if the male failed to enter the pup cage. Males that spent a minimum of $3 \mathrm{~min}$ in contact with the pup, licking and grooming, or huddling with the pup were classified as alloparental. Because all control males were alloparental, for the purpose of analysis they were grouped.

Social preference. Five days after the alloparental test, treated males were tested for social preference. This was done using the standardized vole partner preference test (Liu et al., 2001; Cushing et al., 2003). Treated males were cohabited with an unrelated sexually naive adult female for $1 \mathrm{~h}$. This female was classified as the familiar "partner." Female prairie voles do not undergo spontaneous estrus and require prolonged exposure to a male to become sexually receptive. Therefore, mating is not a factor in this test. Immediately after cohabitation, test animals participated in a social preference test. The social preference arena consisted of three polycarbonate cages $(12 \times 18 \times 28 \mathrm{~cm})$ in a modified $Y$ shape. The two cages housing stimulus animals were in parallel and a third cage (neutral) was attached separately to each stimulus cage. The familiar female was gently tethered in one of the stimulus cages while an age- and size-matched sexually naive female (novel/“stranger") that was unrelated to both the familiar female and the subject was tethered in the other stimulus cage. Then, the experimental male was placed in the neutral chamber and allowed to move about freely for $3 \mathrm{~h}$. The test was recorded using a time-lapse video (12:1 ratio) and then scored by an experimentally blind scorer. The data scored and analyzed include frequency of entrance, total time spent in the chambers, and time spent in physical contact with partner and stranger. It should be noted that without hormonal manipulation, such as central administration of arginine vasopressin, $1 \mathrm{~h}$ of cohabitation does not lead to the formation of preference for the familiar stimulus animal (DeVries et al., 1996; Cho et al., 1999); therefore, control males were predicted to spend equal amounts of time in the cages of and in physical contact with both females.

Statistical analysis. Based on the a priori assumption that the two control groups would not differ, preplanned comparisons were made between the two controls. If and only if there was no difference in any measure, they were grouped into a single control group for the purpose of analysis, which was the case in this study. Alloparental data represents count data with two possible outcomes; therefore the data were analyzed using $2 \times 2$ Fisher's exact probability. For the social preference test, an ANOVA was used to analyze between treatment effects, whereas a paired $t$ test was used for within-treatment analysis.

\section{Results}

As indicated by immunoreactivity of transfected ER $\alpha 12$ (eight bilateral and four unilateral) of the 20 males in which AAV-ER $\alpha$ was injected into the MeA were successfully transfected (Fig. 1a). There were a total of 19 control males ( 9 MeA luciferase and 10 caudate $\mathrm{ER} \alpha$ ). There was a significant treatment effect of increased $\mathrm{ER} \alpha$ in the MeA on both the expression of spontaneous alloparental behavior and social preference. Enhancing ER $\alpha$ in the MeA inhibited alloparental behavior with only 4 of 12 (33\%) MeA-ER $\alpha$ males displaying alloparental behavior, compared with 19 of $19(100 \%)$ of the control males (Fisher's exact $p<$ 0.0001) (Fig. 2). Nonalloparental behavior displayed by MeAER $\alpha$ males included attacking the pup $(n=5)$, attempting to mount and mate with the pup $(n=2)$, or ignoring the pup $(n=$ $1)$. As predicted, control males did not display a preference for either the familiar or novel female. In contrast, MeA-ER $\alpha$ males 

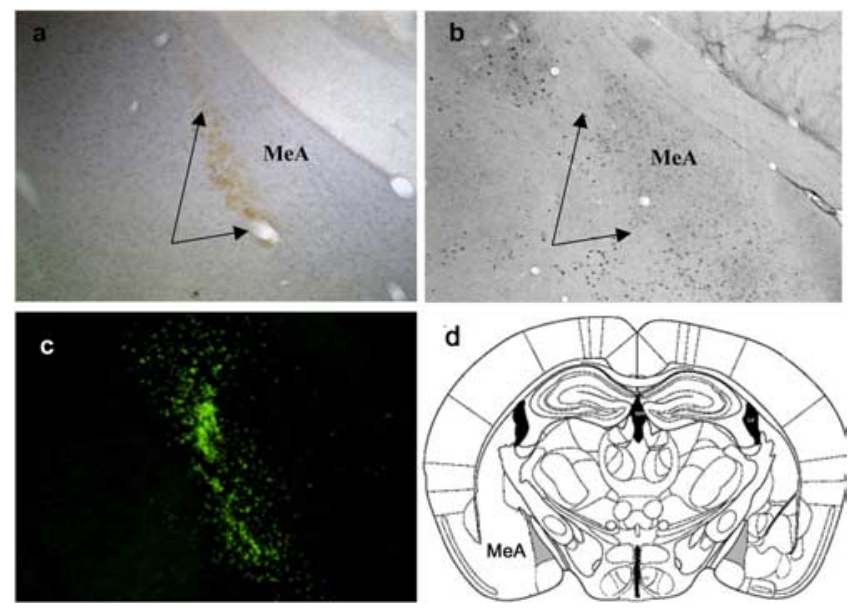

Figure 1. a, Photomicrograph of AAV-mediated ER $\alpha$ overexpression. $\boldsymbol{b}$, Typical low levels of $\mathrm{ER} \alpha$ immunoreactivity in the medial amygdala of male prairie voles. c, GFP expression. $\boldsymbol{d}$, Graphic representation of the site of infusion (gray shaded area) (adapted from Paxinos and Franklin, 2001). Endogenous vole $\operatorname{ER} \alpha(\boldsymbol{a})$ is labeled using the primary polyclonal antibody C1355 (Millipore; 1:10,000 dilution) and developed with nickel-DAB (purple staining) (Cushing et al., 2004), whereas transfected human $E R \alpha$ is labeled using the primary antibody RM9101-s (1:1000 dilution) and visualized using DAB (brown).

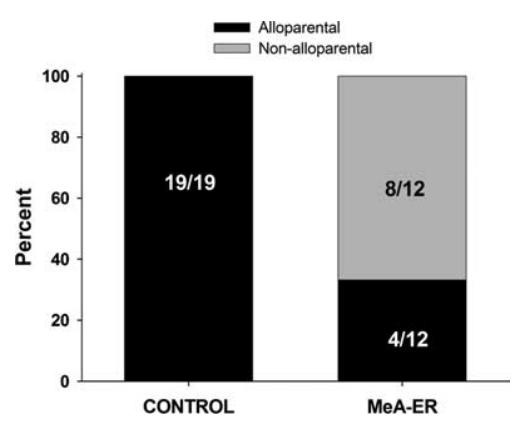

Figure 2. Results of treatment on the expression of spontaneous alloparental behavior. Enhancing $E P \alpha$ in the MeA (MeA-ER $\alpha$ ) resulted in a significant decrease in alloparental behavior compared with control males. $p<0.001$.

spent significantly more time in a novel female's cage compared with control males (ANOVA, $p<0.05$ ) (Fig. 3). MeA-ER $\alpha$ males formed a "stranger" preference spending significantly more time in the cage of a novel female (pair $t$ test, $p<0.05$ ) and in physical contact with a novel female than with a familiar female (paired $t$ test, $p<0.05$ ) (Fig. 3).

\section{Discussion}

The results from this study indicate the importance of $\mathrm{ER} \alpha$ in regulating male prosocial behavior providing direct evidence that $\mathrm{ER} \alpha$ can inhibit the expression of male prosocial behavior. Furthermore, the results support the hypothesis that a reduction in $\mathrm{ER} \alpha$ is necessary for the expression of high levels of male prosocial behavior. Increasing ER $\alpha$ in the MeA of the adult male prairie vole reduced or inhibited the expression of alloparental behavior and the initial formation of social preferences.

Unlike most male rodents, which are infanticidal or ignore pups, even inexperienced male prairie voles display high levels of spontaneous alloparental behavior, including licking, grooming, huddling, and retrieving unrelated pups. In the majority of males, enhancing ER $\alpha$ in the MeA produced a more "typical" male response that of pup-directed aggression, although in two males it produced a novel response: pup-directed sexual activity. The ex-

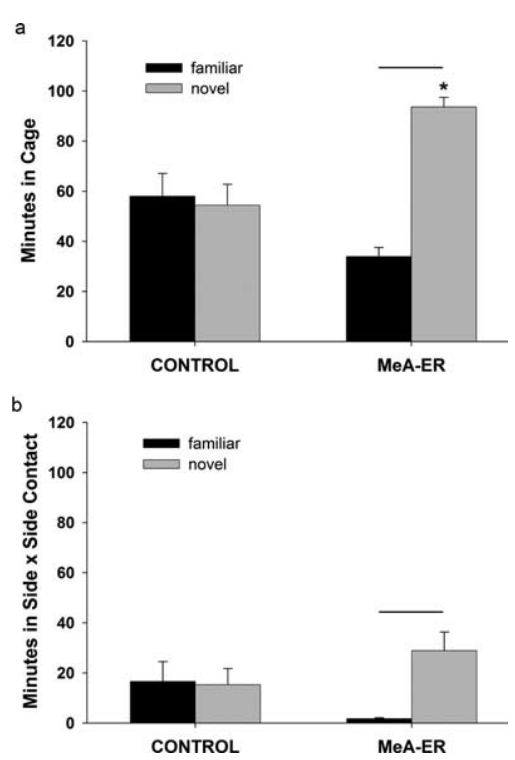

Figure 3. $\quad \boldsymbol{a}$, Mean time ( $\pm \mathrm{SE}$ ) that males spent in the cage of the familiar or novel female by treatment. $\boldsymbol{b}$, Mean time ( $\pm \mathrm{SE}$ ) in side-by-side contact with the familiar and novel female by treatment. MeA-ER $\alpha$ males spent significantly less time in the familiar female cage and significantly more time in the novel female cage than control males $(p \leq 0.05)$. Within-treatment analysis revealed that MeA-ER $\alpha$ males displayed a preference for the novel female spending significantly more time in the novel female cage than the familiar female cage, and more time in side-by-side contact with the novel female. ${ }^{*} p<0.05$, significant between treatment difference; line above error bars shows significant difference within treatment, $p<0.05$. Error bars indicate SEM.

pression of spontaneous alloparental behavior is very difficult to disrupt in male prairie voles (Cushing and Kramer, 2005a), and although it has been suggested that alloparental behavior is controlled by neuropeptides, inhibition of endogenous neuropeptides does not disrupt the alloparental behavior in adult males. However, neonatal castration does disrupt male alloparental behavior (Lonstein et al., 2002) as well as significantly increasing $\mathrm{ER} \alpha$ in the MeA (Cushing and Kramer, 2005b). These findings suggest that steroids play a major role in facilitating and perhaps organizing the male's response to pups. The fact that increasing $\mathrm{ER} \alpha$ in adults and removal of testes from neonates both inhibit the expression of alloparental behavior suggests that a low threshold level of steroid is necessary for the expression of alloparental behavior, but that higher levels masculinize behavior.

Enhancing ER $\alpha$ in the MeA clearly altered alloparental behavior. However, there was variability in the response. Although the sample size was insufficient to determine the reason for the variability, it is possible that differential enhancement of $\operatorname{ER} \alpha$ could explain part of the variation. Variation could have been related to unilateral versus bilateral enhancement of ER $\alpha$. Although it has been hypothesized that the right and left amygdala may differentially regulate behavior (Cooke et al., 2007), empirical studies that have compared unilateral versus bilateral effects in the amygdala suggest that there is no difference as unilateral and bilateral lesions produce the same effect on behavior [MeA, Sheehan et al. (2001); basolateral, Floresco and Ghods-Sharifi (2007)]. Additionally, the degree of enhancement could have affected the response. It is possible that animals with more $\mathrm{ER} \alpha$ responded differently than those with less. Finally, it could be a combination of the degree of enhancement and unilateral versus bilateral ER $\alpha$. Future studies will be designed to determine whether the right and left side of the amygdala play different roles in regulating social behavior. 
Although male prairie voles form long-term pair bonds, this process requires either extended cohabitation or central administration of the neuropeptide vasopressin (Insel and Young, 2001). Control males displayed the predicted response, spending an equal amount of time with the familiar and the novel female, whereas MeA-ER $\alpha$ males formed a preference for a novel female, spending significantly more time in contact with the novel female. This result is similar to observations of male mice in that after spending time with a nonreceptive female, males prefer a novel female when given a choice (Moy et al., 2004). The preference for a novel female is particularly relevant when considered in light of the numerous studies of social preference in prairie voles and the function of neuropeptides. In has been argued that neuropeptides are primarily responsible for the formation of pair bonds (Keverne and Curley, 2004; Young and Wang, 2004; Nair and Young, 2006). Vasopressin and oxytocin antagonists inhibited the formation of a partner preference or inhibited social contact, but did not result in the formation of a preference for a novel female (Cho et al., 1999). These results suggest that ER $\alpha$ expression significantly alters the normal steps involved in the formation of social preference. Interestingly, the only other study in which male prairie voles formed a preference for a novel female also involved steroidal manipulation through adrenalectomies followed by treatment with corticosterone (DeVries et al., 1996).

Although several mechanisms have been proposed to regulate the formation of pair bonds, the neuropeptide arginine vasopressin has been proposed to be the primary mechanism involved in regulating pair bond formation and parental behavior in male prairie voles (Young and Wang, 2004). Although we are not suggesting that the current results negate the role of vasopressin, they clearly demonstrate that there are critical aspects of social bonding that have not previously been investigated and that $\mathrm{ER} \alpha$ plays a critical role. The results from this study bring into question the assumption that the pattern of the vasopressin V1a receptor (V1aR) is sufficient to explain the formation of pair bonds. Neonatal castration is one of the few reported methods to disrupt alloparental behavior in adult male prairie voles (Lonstein et al., 2002). Adult males that were castrated neonatally display a female pattern of $\mathrm{ER} \alpha$ and females display low levels of alloparental behavior (Cushing and Kramer, 2005b). Neonatal castration also inhibited the subsequent ability of centrally administered vasopressin to stimulate partner preferences in adult males, but did not alter the expression of V1aR (Cushing et al., 2003), indicating that the lack of response was not caused by changes in the ability to respond to vasopressin. Chimeric male mice that express prairie vole V1aR display a prairie vole-like pattern of $\mathrm{V} 1 \mathrm{aR}$ and an increase in general social affiliation (Young et al., 1999), but do not develop a partner/social preference. One possibility is that social preferences were absent in these transgenic mice because ER $\alpha$ expression was unchanged from the normal pattern, which includes high levels in the MeA. Prairie voles display variation in the length of a microsatellite in the V1aR promoter and length is positively correlated with the expression of prosocial behavior; additionally, this element in the V1aR of the polygynous montane and meadow voles is substantially shorter (Hammock and Young, 2004; Hammock et al., 2005). However, the assertion that the length of this microsatellite is the key element in prosocial behavior has recently been challenged with the finding that many other species in the genus Microtus that do not express high levels of social behavior also display significant variation in V1aR microsatellite length (Fink et al., 2006). This finding lead to the suggestion that other factors/genes must also be involved in the ultimate formation of long-term pair bonds. Although montane and meadow voles express the same V1aR microsatellite and the same pattern of V1aR in the brain, meadow voles display prosocial behavior in response to centrally administered vasopressin, whereas montane males do not (Young et al., 1999). They do, however, differ in $\mathrm{ER} \alpha$ expression with meadow vole male expressing an intermediate pattern between montane and prairie (Cushing and Wynne-Edwards, 2006). We suggest that the current findings indicate that a reduction in $\operatorname{ER} \alpha$ may also be necessary.

The formation of long-term social bonds is a complex process that has been proposed to involve at least two neural circuits, the social behavior neural circuit and the reward system (Young et al., 2005). It has been proposed that within these circuits the ventral pallidum (Lim et al., 2001) and lateral septum (Liu et al., 2001) play an essential role in pair bond formation in males, and the bed nucleus of the stria terminalis in male parental care (De Vries and Villalba, 1997). Here, we show that altering receptor patterns of a nucleus upstream of these regions is sufficient to alter the behavioral response to social stimuli. This does not negate the critical role of the lateral septum or reward system in the expression of social behavior, but clearly demonstrates that changes in the initial response to social stimuli can prevent potentiation of these areas. This also presents the possibility that variable responses can be produced from the same system by altering ER $\alpha$ expression, seasonally or otherwise, to change how the neural circuit regulates social behavior. The findings in this study do not imply that the MeA directly regulates pup-directed aggression or the formation of pair bonds, but that changing the receptor pattern can change the response of the whole circuit and dramatically alter the ultimate response. This conclusion is emphasized by the observation that MeA-ER $\alpha$ males mounted and thrust against the pup. Of the thousands of alloparental tests that have been run with prairie voles, this has never been reported, and supports the concept that altering receptor expression can result in misdirected behavior.

\section{References}

Cho MM, DeVries AC, Williams JR, Carter CS (1999) The effects of oxytocin and vasopressin on partner preferences in male and female prairie voles (Microtus ochrogaster). Behav Neurosci 113:1071-1079.

Clark KR, Liu X, McGrath JP, Johnson PR (1999) Highly purified recombinant adeno-associated virus vectors are biologically active and free of detectable helper and wild-type viruses. Hum Gene Ther 10:1031-1039.

Cooke BM, Stokas MR, Woolley CS (2007) Morphological sex differences and laterality in the prepubertal medial amygdala. J Comp Neurol 501:904-915.

Cushing BS, Kramer KM (2005a) Microtines: a model system for studying the evolution and regulation of social monogamy. Acta Theriol Sin 25:182-199.

Cushing BS, Kramer KM (2005b) Mechanisms underlying epigenetic effects of early social experience: the role of neuropeptides and steroids. Neurosci Biobehav Rev 29:1089-1115.

Cushing BS, Wynne-Edwards KE (2006) Estrogen receptor alpha distribution in male rodents is associated with social organization. J Comp Neurol 494:595-605.

Cushing BS, Okorie U, Young LJ (2003) The effects of early exposure of testosterone on the subsequent response of adult male prairie voles to arginine vasopressin. J Neuroendocrinol 15:1021-1026.

Cushing BS, Razzoli M, Murphy AZ, Epperson PM, Le WW, Hoffman GE (2004) Intraspecific variation in estrogen receptor alpha and the expression of male sociosexual behavior in two populations of prairie voles. Brain Res 1016:247-254.

DeVries AC, DeVries MB, Taymans SE, Carter CS (1996) The effects of stress on social preferences are sexually dimorphic in prairie voles. Proc Natl Acad Sci U S A 93:11980-11984.

De Vries GJ, Villalba C (1997) Brain sexual dimorphism and sex differences in parental and other social behaviors. Ann N Y Acad Sci 807:273-286. 
Ferguson JN, Aldag JM, Insel TR, Young LJ (2001) Oxytocin in the medial amygdala is essential for social recognition in the mouse. J Neurosci 21:8278-8285.

Fink S, Excoffier L, Heckel G (2006) Mammalian monogamy is not controlled by a single gene. Proc Natl Acad Sci U S A 103:10955-10960.

Floresco SB, Ghods-Sharifi S (2007) Amygdala-prefrontal cortical circuitry regulates effort-based decision making. Cereb Cortex 17:251-260.

Hammock EA, Young LJ (2004) Functional microsatellite polymorphism associated with divergent social structure in vole species. Mol Biol Evo 21:1057-1063.

Hammock EA, Lim MM, Nair HP, Young LJ (2005) Association of vasopressin la receptor levels with a regulatory microsatellite and behavior. Genes Brain Behav 4:289-301.

Hnatczuk OC, Lisciotto CA, DonCarlos LL, Carter CS, Morrell JI (1994) Estrogen and progesterone receptor immunoreactivity (ER-IR and PRIR) in specific brain areas of the prairie vole (Microtus ochrogaster) is altered by sexual receptivity and genetic sex. J Neuroendocrinol 6:89-100.

Insel TR, Young LJ (2001) The neurobiology of social attachment. Nat Rev Neurosci 2:129-136.

Keverne KB, Curley JP (2004) Vasopressin, oxytocin and social behaviour. Curr Opin Neurobiol 14:777-783.

Kramer KM, Simmons JL, Freeman DA (2008) Photoperiod alters central distribution of estrogen receptor $\alpha$ in brain regions that regulate aggression. Horm Behav 53:358-365.

Krezel W, Dupont S, Krust A, Chambon P, Chapman PF (2001) Increased anxiety and synaptic plasticity in estrogen receptor $\beta$-deficient mice. Proc Natl Acad Sci U S A 98:12278-12282.

Kudwa AE, Bodo C, Gustafsson JA, Rissman EF (2005) A previously uncharacterized role for estrogen receptor beta: defeminization of male brain and behavior. Proc Natl Acad Sci U S A 102:4608-4612.

Lim MM, Insel TR, Young LJ (2001) The ventral pallidum in the monogamous prairie vole: neuroanatomy and activity. Horm Behav 39:336-337.

Liu Y, Curtis JT, Wang ZX (2001) Vasopressin in the lateral septum regulates pair bond formation in male prairie voles (Microtus ochrogaster). Behav Neurosci 115:910-919.

Lonstein JS, Rood BD, De Vries GJ (2002) Parental responsiveness is feminized after neonatal castration in virgin male prairie voles, but not mas- culinized by perinatal testosterone in virgin females. Horm Behav 41:80-87.

Moy SS, Nadler JJ, Perez A, Barbaro RP, Johns JM, Magnuson TR, Piven J, Crawley JN (2004) Sociability and preference for social novelty in five inbred strains: an approach to assess autistic-like behavior in mice. Genes Brain Behav 3:287-302.

Musatov S, Chen W, Pfaff DW, Kaplitt MG, Ogawa S (2006) RNAimediated silencing of estrogen receptor $\{$ alpha\} in the ventromedial nucleus of hypothalamus abolishes female sexual behaviors. Proc Natl Acad Sci U S A 103:10456-10460.

Nair HP, Young LJ (2006) Vasopressin and pair-bond formation: genes to brain to behavior. Physiology 21:146-152.

Newman SW (1999) The medial extended amygdala in male reproductive behavior. A node in the mammalian social behavior network. Ann N Y Acad Sci 877:242-257.

Ogawa S, Washburn TF, Taylor J, Lubahn DB, Korach KS, Pfaff DW (1998) Modifications of testosterone-dependent behaviors by estrogen receptoralpha gene disruption in male mice. Endocrinology 139:5058-5069.

Paxinos G, Franklin KB (2001) The mouse brain in stereotaxic coordinates, Ed 2. San Diego: Academic.

Sheehan T, Paul M, Amaral E, Numan MJ, Numan M (2001) Evidence that the medial amygdala projects to the anterior/ventromedial hypothalamic nuclei to inhibit maternal behavior in rats. Neuroscience 106:341-356.

Trainor BC, Greiwe KM, Nelson RJ (2006) Individual differences in estrogen receptor a in select brain nuclei are associated with individual differences in aggression. Horm Behav 50:338-345.

Wersinger SR, Sannen K, Villalba C, Lubahn DB, Rissman EF, De Vries GJ (1997) Masculine sexual behavior is disrupted in male and female mice lacking a functional estrogen receptor alpha gene. Horm Behav 32:176183.

Young LJ, Wang ZX (2004) The neurobiology of pair bonding. Nat Neurosci 7:1048-1054.

Young LJ, Nilsen R, Waymire KG, MacGregor GR, Insel TR (1999) Increased affiliative response to vasopressin in mice expressing the vasopressin receptor from a monogamous vole. Nature 400:766-768.

Young LJ, Murphy-Young AZ, Hammock EA (2005) Anatomy and neurochemistry of the pair bond. J Comp Neurol 493:51-57. 